\title{
Informal care and the impact on depression and anxiety among Swedish adults: a population-based cohort study
}

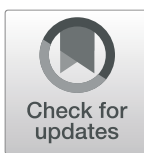

Marlene Stratmann, Yvonne Forsell, Jette Möller and Yajun Liang*

\begin{abstract}
Background: As the population is ageing, the need for informal caregivers increases, and thus we need to know more about the effects on caregivers. This study aims to determine both cross-sectional and longitudinal associations between perceived limitation of informal caregiving and mental health of caregivers.

Methods: This population-based cohort study was based on the Swedish Psykisk hälsa, Arbete och RelaTioner (PART) study, and 9346 individuals aged 18-65 were included. Data were collected through questionnaires, interviews and Swedish registers. Informal care was defined as care given to a family member. Self-reported and diagnosed depression and anxiety were included as outcomes. Covariates included sex, age, social support and socio-economic position. Ordinal logistic regression and Cox regression were performed to determine the associations between caregiving and anxiety or depression.
\end{abstract}

Results: Self-reported depression and anxiety was only increased among those experiencing limitations (adjusted odds ratios [aOR] 2.00, 95\% confidence intervals [Cl] 1.63-2.47 for depression; aOR 2.07, 95\% Cl 1.57-2.74 for anxiety) compared to those not giving care, respectively. The adjusted hazard ratio (aHR) were increased for diagnosed depression (aHR 1.97, 95\% Cl 1.27-3.05) and for diagnosed anxiety (aHR 1.86, 95\% Cl 1.06-3.25) among those giving care and experiencing limitations, compared to those not giving care. No significant associations were found in caregivers without limitations.

Conclusion: Caregivers experiencing limitations showed a significant association with short- and long-term anxiety and depression. This study implies the importance of exploring the degree to which informal caregiving can be provided without adding burden to caregivers.

Keywords: Informal caregiving, Cohort, Depression, Anxiety

\section{Introduction}

Informal caregiving is defined as the care given to a family member (family caregiving), friend or neighbour including emotional and practical help, and is typically unpaid [1]. Furthermore, informal care is usually homebased [1]. In contrast, formal care is a paid service provided by trained healthcare professionals that can be

\footnotetext{
* Correspondence: yajun.liang@ki.se

Department of Global Public Health, Karolinska Institutet, Tomtebodavägen 18A, 17177 Stockholm, Sweden
}

carried out as home-based care, community-based care or residential care [2]. Both informal and formal care include assistance in personal and clinical care and homemaking [2].

According to the Organization for Economic Cooperation and Development (OECD), one in three individuals aged 50 years and above are giving informal care to some degree [3], which complies with the estimates of the European Social Survey Round 7 [4]. In Sweden, the estimates of persons over the age of 18 years that provide

(c) The Author(s). 2021 Open Access This article is licensed under a Creative Commons Attribution 4.0 International License, which permits use, sharing, adaptation, distribution and reproduction in any medium or format, as long as you give appropriate credit to the original author(s) and the source, provide a link to the Creative Commons licence, and indicate if changes were made. The images or other third party material in this article are included in the article's Creative Commons licence, unless indicated otherwise in a credit line to the material. If material is not included in the article's Creative Commons licence and your intended use is not permitted by statutory regulation or exceeds the permitted use, you will need to obtain permission directly from the copyright holder. To view a copy of this licence, visit http://creativecommons.org/licenses/by/4.0/ The Creative Commons Public Domain Dedication waiver (http://creativecommons.org/publicdomain/zero/1.0/) applies to the data made available in this article, unless otherwise stated in a credit line to the data. 
informal care differ from $20 \%$ up to $29 \%[1,4]$. As of now, on average $60 \%$ of all care in EU countries has been provided by informal caregivers in 2012, with variations across countries [5]. Based on a changing demography with less young people and more elders [3, 6-9], the need for informal caregiving will increase in the future [10]. Furthermore, European governments are retreating from the responsibility of home care and with a smaller proportion of young people being in the work force compared to a bigger proportion of retired people, the labour market might be unable to handle the challenge of an increased need for informal caregivers [9, 10]. Estimations suggest a future deficit of 20,000 informal caregivers in the Netherlands and 400,000 in Germany by 2060 [8].

While the most common reason of informal caregiving is long-lasting illness or disability in older family members, such as dementia, it can also lead to illness in the caregiver her- or himself [10,11]. Even though studies have reported on positive outcomes of informal caregiving such as an increased positive appraise and occasionally a better well-being [7, 12], informal caregiving has mainly been associated with worse physical and mental health, such as depression, anxiety and burn-out [2, 8, 13-18]. Most studies regarding informal caregiving and mental health focus on the state of mental health in general or perceived stress in the informal caregiver $[3,17$, $19,20]$. It has been stated that in OECD countries informal caregivers suffer $20 \%$ more from a mental illness than non-caregivers [3].

Generally, informal care is mostly provided by women, although the proportion of men has been increasing in the last years $[2,21,22]$. Especially as the carers grow older, the proportion of men providing informal care increases [3]. In Sweden, the proportion of women and men providing informal care is equal $[1,23]$. Yet, the tasks carried out by men and women are different [1]. While women provide help with personal care and serve as interlocutor, men usually provide financial support and practical help [1]. Additionally, previous research has shown that women experience mental ill health, such as depression and anxiety, up to two times more often than men in general [6, 19-21, 24, 25].

So far, it is unclear to what extent informal caregiving impacts anxiety and depression. The association between informal caregiving and anxiety has often been implied in reports and reviews, however, there are very few population-based studies estimating the association between informal caregiving and risk of anxiety and depression $[6,8,17]$. Two reports suggest an increased risk of mental ill-health if participants provide informal care, and one study estimated the same association but could not conclude a statistically significant association $[6,8$, 17]. In addition to the duty of giving care itself, perceived limitations due to caregiving, referring to the negative influence on the personal life of caregivers, are hypothesized to be the crucial underlying reasons for mental illness of caregivers. So far, the evidence is lacking on the effect of perceived limitation of caregiving on the mental health outcomes. Thus, the aim of this study was to determine both cross-sectional and longitudinal associations between perceived limitation of informal caregiving and mental health of caregivers.

\section{Methods \\ Study design}

Data were used from the Swedish PART (In Swedish short for: Psykisk hälsa, Arbete och RelaTioner) study, which is an ongoing longitudinal cohort study. Based on the PART study, a cross-sectional study design was used to estimate the self-reported outcomes from wave 1 (baseline) and a longitudinal cohort study design was used to estimate clinically diagnosed outcomes and longitudinal self-reported outcomes from the follow-up questionnaire (wave 3). This study included data from wave 1 (1998-2000), wave 3 (2010) and Swedish registers (1998-2014). Those who answered the questionnaire in wave 1 were followed up in wave 3 and afterwards linked to Swedish inpatient and outpatient registers and the cause of death register.

\section{Study participants}

At baseline, a total of 19,457 persons were invited to participate and 10,345 responded (53\%). The participants were more likely to be female, older, with higher education and income, born in the Nordic countries and without previous diagnosis of psychiatric conditions [26]. The study population (wave 1) included 10,345 participants aged 18-65 years old living in Stockholm, Sweden. After excluding 18 participants with missing information on caregiving, 7 with missing date of entry and 974 that reported previous depression or anxiety in the baseline questionnaire, the final study population included 9346 participants at baseline for the cross-sectional analyses. Of those, 5108 answered the follow-up questionnaire 10 years later and were included for the longitudinal analyses.

\section{Informal caregiving}

The exposure was defined as informal caregiving to a family member and assessed according to a positive response to the question "Are you currently responsible for the care of a long-time sick or disabled family member?" In order to assess the perceived limitations that informal caregiving can have on the life of the caregiver, three follow up questions were asked regarding conflicts with work, leisure time, and family or friends due to informal caregiving. The exact questions asked were: Are 
your opportunities for work or leisure activities limited by this care responsibility? Are your opportunities for spending time with friends and family limited by this care responsibility? Does your responsibility for care lead to conflicts with family or friends? The response alternatives included: no, yes to some degree, and yes to a high degree. Based on this, three exposure categories were defined: no caregiving, caregiving with no limitations and caregiving with any degree or dimension of limitations in the caregiver's life.

\section{Depression and anxiety}

This study focuses on depression and anxiety as outcomes. Using the major depression inventory (MDI), self-reported depressive symptoms were classified into four categories: no depressive symptoms $(<20)$, mild (20-24), moderate (25-29) and severe (>30) depressive symptoms. Anxious distress was assessed by using the DSM-5 criteria consisting of five questions from three different scales [27]. These questions were related to feeling keyed up or tense, feeling unusually restless, difficulty in concentrating because of worry or fear of losing self-control, fear that something awful might happen and fear of losing self-control. Self-reported anxious distress was categorised into mild and moderate/severe as severe anxious distress requires a clinical observation of motor agitation [27].

Diagnosed depression was defined as having a diagnosis of either major depressive disorder with a single episode or recurrent depressive disorder (ICD-10 codes: F32-33) in the Swedish in- and outpatient register. Clinically diagnosed anxiety was defined as either having phobic anxiety disorders or other anxiety disorders (ICD-10 codes: F40-41) in the same registers as mentioned previously.

\section{Covariates}

Covariates included age, sex, social support and socioeconomic position. Social support was categorised into yes and no and assessed whether the participant had one specific person they felt supported by. According to statistics Sweden, socio-economic position was grouped into categories containing unskilled or semi-killed, skilled, assistant non-manual, student, age or early retirement, self-employed, employed, unemployed or on sick leave or on leave, and others that contain part-time work and duties [28]. Information about the covariates were based on information from the first wave of PART.

\section{Statistical analysis}

Descriptive analysis was reported as mean (standard deviation) for continuous variables and as number (percentage) for categorical variables. The follow-up time started from the date of receiving the questionnaire and ended at the date of outcome, death or 31. December 2014, whichever came first. To determine the associations of informal caregiving with depression and anxiety, two different methods were used. For the self-reported depression and anxiety at baseline and 10-year followup, ordinal logistic regression models were used to determine odds ratio (OR) and 95\% confidence interval (CI). For the diagnosed depression and anxiety, Cox proportional hazard regression models were used for the estimation of hazard ratio (HR) and 95\% CI. Two models were reported from both the ordinal logistic regression and the Cox proportional hazard regression analyses: model 1 was crude, and model 2 was adjusted for sex, age, socio-economic position and social support. In addition, baseline self-reported depression and anxiety were further adjusted in the ordinal logistic regression models for the 10-year follow-up analysis. A sensitivity analysis using cox proportional hazard regression was performed, restricting analyses to those participants that participated in both the baseline and 10-year follow-up to check if the loss to follow-up had an effect on the associations. All analyses were carried out in the statistical programme Stata, version 16.

\section{Results}

As shown in Table 1, the proportion of women was highest in those giving informal care and experiencing limitations. Informal caregivers in general were older compared to participants that did not provide informal care. Social support was more common among participants that did not give care and those that gave care but did not experience limitations. The study participants that gave informal care were more often retired or unemployed.

The prevalence of self-reported depressive symptoms was $8.50 \%$ for mild depressive symptoms, $4.23 \%$ for moderate depressive symptoms and $7.41 \%$ for severe depressive symptoms at baseline and $3.71 \%$ for mild depressive symptoms, $1.84 \%$ for moderate depressive symptoms and $3.04 \%$ for severe depress depressive symptoms at 10-year follow-up. The 15-year cumulative incidence for clinically diagnosed depression was $2.63 \%$.

For self-reported anxious distress, the prevalence was $5.2 \%$ for mild anxious distress and 3.3\% for moderate to severe anxious distress at baseline. At 10-year follow-up the prevalence was $2.02 \%$ for mild anxious distress and $1.22 \%$ for moderate to severe anxious distress. The 15year cumulative incidence for clinically diagnosed anxiety was $1.84 \%$.

In Table 2, the crude ORs for both depressive symptoms (OR 1.85, 95\% CI 1.52-2.26) and anxious distress (OR 1.91, 95\% CI 1.46-2.49) were significantly higher in the informal caregivers experiencing limitations 
Table 1 Baseline characteristics of the study population by informal caregiving ( $n=9346)$

\begin{tabular}{llll}
\hline & $\begin{array}{l}\text { No caregiving } \\
(\boldsymbol{n}=\mathbf{8 5 6 2})\end{array}$ & $\begin{array}{l}\text { Caregiving without limitations } \\
(\boldsymbol{n}=\mathbf{3 1 2})\end{array}$ & $\begin{array}{l}\text { Caregiving with limitations } \\
(\boldsymbol{n}=\mathbf{4 7 2})\end{array}$ \\
\hline $\begin{array}{l}\text { Age, years, mean (SD) } \\
\text { Sex, } n \text { (\%) }\end{array}$ & $41(12)$ & $48(11)$ & $46(11)$ \\
Man & $3972(46.4)$ & $134(42.9)$ & $152(32.2)$ \\
Woman & $4590(53.6)$ & $178(57.1)$ & $320(67.8)$ \\
Social support, $n$ (\%) & & & $438(92.8)$ \\
Yes & $8072(94.3)$ & $296(94.9)$ & $34(7.2)$ \\
No & $490(5.7)$ & $16(5.1)$ & $11(2.3)$ \\
Socioeconomic position, $n$ (\%) & & & $9(1.9)$ \\
Unskilled/semi-skilled & $164(1.9)$ & $4(1.3)$ & $15(3.2)$ \\
Skilled & $54(0.6)$ & $2(0.6)$ & $25(5.3)$ \\
Assistant non-manual & $142(1.7)$ & $5(1.6)$ & $34(7.2)$ \\
Student & $639(7.5)$ & $8(2.6)$ & $35(7.4)$ \\
Retired & $408(4.8)$ & $22(7.1)$ & $264(55.9)$ \\
Self-employed & $607(7.1)$ & $23(7.4)$ & $47(10.0)$ \\
Employed & $5402(63.1)$ & $200(64.1)$ & $32(6.8)$ \\
Unemployed/sick leave & $726(8.5)$ & $28(9.0)$ & $(6.4)$ \\
Others & $420(4.9)$ & & \\
\hline
\end{tabular}

Table 2 The association between informal caregiving and self-reported depressive symptoms and anxious distress at baseline and 10-year follow-up

\begin{tabular}{|c|c|c|c|c|c|}
\hline & \multirow{2}{*}{$\begin{array}{l}\text { No. of } \\
\text { participants }\end{array}$} & \multirow{2}{*}{$\begin{array}{l}\text { No. } \\
\text { of } \\
\text { cases }\end{array}$} & \multicolumn{3}{|c|}{ Odds ratios $\left(95 \%\right.$ confidence interval) ${ }^{a}$} \\
\hline & & & Model 1 & Model 2 & Model 3 \\
\hline \multicolumn{6}{|l|}{ Baseline $(n=9346)$} \\
\hline \multicolumn{6}{|c|}{ Self-reported depressive symptoms } \\
\hline No caregiving & 8562 & 1683 & 1 (ref.) & 1 (ref.) & \\
\hline Caregiving without limitations & 312 & 53 & $0.83(0.62-1.12)$ & $0.96(0.70-1.32)$ & \\
\hline Caregiving with limitations & 472 & 146 & $1.85(1.52-2.26)$ & $2.00(1.63-2.47)$ & \\
\hline \multicolumn{6}{|l|}{ Self-reported anxious distress } \\
\hline No caregiving & 8562 & 714 & 1 (ref.) & 1 (ref.) & \\
\hline Caregiving without limitations & 312 & 20 & $0.76(0.48-1.20)$ & $0.89(0.55-1.45)$ & \\
\hline Caregiving with limitations & 472 & 69 & $1.91(1.46-2.49)$ & $2.07(1.57-2.74)$ & \\
\hline \multicolumn{6}{|l|}{ 10-year follow-up ( $n=5108)$} \\
\hline \multicolumn{6}{|c|}{ Self-reported depressive symptoms } \\
\hline No caregiving & 4626 & 721 & 1 (ref.) & 1 (ref.) & 1 (ref.) \\
\hline Caregiving without limitations & 197 & 22 & $0.68(0.44-1.07)$ & $0.82(0.52-1.31)$ & $0.86(0.53-1.40)$ \\
\hline Caregiving with limitations & 285 & 60 & $1.43(1.07-1.91)$ & $1.44(1.06-1.96)$ & $1.13(0.81-1.57)$ \\
\hline \multicolumn{6}{|l|}{ Self-reported anxious distress } \\
\hline No caregiving & 4626 & 269 & 1 (ref.) & 1 (ref.) & 1 (ref.) \\
\hline Caregiving without limitations & 197 & 10 & $0.87(0.45-1.66)$ & $1.04(0.53-2.03)$ & $1.11(0.56-2.19)$ \\
\hline Caregiving with limitations & 285 & 24 & $1.49(0.97-2.31)$ & $1.52(0.96-2.41)$ & $1.23(0.76-1.99)$ \\
\hline
\end{tabular}

a Model 1 was a crude model; model 2 was adjusted for age, sex, social support and socio-economic position; model 3 was additionally adjusted for baseline MDI or rating scale for anxious distress for each outcome respectively 
compared to those that did not give care. These ORs even increased after adjusting for confounding factors for self-reported depressive symptoms (OR 2.00, 95\% CI 1.63-2.47) and self-reported anxious distress (OR 2.07, 95\% CI 1.57-2.74) in the informal caregivers who experienced limitations compared with those without informal caregiving. When repeating the measurement at the 10-year follow-up, the informal caregivers experiencing limitations still had increased ORs for self-reported depressive symptoms in the crude (OR 1.43, 95\% CI 1.071.91) and adjusted model (adjusted odds ratio [aOR] 1.44, 95\% CI 1.06-1.96) compared to unexposed participants. Furthermore, when adding the baseline selfreported depressive symptoms in the adjusted model, the OR was not significant. There was no significant association between caregiving with limitation and selfreported anxious distress at 10-year follow-up.

The maximum follow-up time was 16.8 years with an average time to event of 15.5 years for diagnosed depression and 15.6 years for diagnosed anxiety. In Table 3, the HRs of diagnosed depression and anxiety are shown by status of informal caregiving. Informal caregiving with experiencing limitations was associated with clinically diagnosed depression (adjusted HR [aHR] 1.97, 95\% CI 1.27-3.05) compared to no caregiving after adjustment of covariates, whereas giving informal care without experiencing limitations (aHR 0.71, 95\% CI 0.29-1.74) was not associated with depression. Compared to no informal caregiving, informal caregiving with limitations was associated with an increased HR for anxiety in the adjusted model (aHR 1.86, 95\% CI 1.06-3.25), while caregiving without limitations was not associated with anxiety (aHR 0.91, 95\% CI 0.33-2.46).

The sensitivity analysis showed increased aHR for diagnosed depression in those caregivers with limitations (aHR 2.07, 95\% CI 1.14-3.78) compared to participants not giving care, however not in those giving care but not experiencing limitations (aHR $0.58,95 \%$ 0.14-2.39) (Additional file 1, Table S1). The results for diagnosed anxiety showed nonsignificant HR for informal caregivers without and with limitations (aHR 0.75, 95\% 0.18-3.08; aHR 1.70, 95\% CI 0.77-3.73), respectively.

\section{Discussion}

We found that caregivers experiencing limitations due to informal caregiving have a 2 -fold increased risk of suffering from anxious distress and depressive symptoms compared to non-caregivers, when studied at the same time. Additionally, we found that informal caregivers that experience limitations in their personal life had an increased risk of depression even 10 years later and a higher hazard of clinically diagnosed depression and anxiety. No significant association was found among those informal caregivers without experiencing any limitations. The perceived limitation but not the act of providing care itself seems to be the crucial factor for mental health outcomes.

We found that the prevalence of self-reported depressive symptoms seemed to decline from baseline to follow-up. This might be partly due to the bias of loss to follow-up such that people with depressive symptoms are less likely to participate in the followup study. However, we did observe a positive association between caregiving with limitations and clinically diagnosed depression and anxiety. This indicates a long-term effect of caregiving with perceived limitations on caregiver's mental health. A review by Petrini et al., found a $40 \%$ increased risk of depression in family caregivers, which is in line with our findings [6]. This review however, only included people giving care to a family member suffering from dementia and the authors specifically state that the rates of depression in the caregivers increase with a larger cognitive impairment in the family member cared for [6].

Table 3 The association between informal caregiving and clinically diagnosed depression and anxiety by informal caregiving $(n=$ $9340^{\mathrm{a}}$ )

\begin{tabular}{|c|c|c|c|c|}
\hline & \multirow{2}{*}{$\begin{array}{l}\text { No. of } \\
\text { participants }\end{array}$} & \multirow{2}{*}{$\begin{array}{l}\text { No. } \\
\text { of } \\
\text { cases }\end{array}$} & \multicolumn{2}{|c|}{ Hazard ratio (95\% confidence interval) } \\
\hline & & & Model 1 & Model 2 \\
\hline \multicolumn{5}{|l|}{ Diagnosed depression } \\
\hline No caregiving & 8558 & 214 & 1 (ref.) & 1 (ref.) \\
\hline Caregiving without limitations & 312 & 5 & $0.64(0.26-1.56)$ & $0.71(0.29-1.74)$ \\
\hline Caregiving with limitations & 470 & 23 & $1.98(1.29-3.04)$ & $1.97(1.27-3.05)$ \\
\hline \multicolumn{5}{|l|}{ Diagnosed anxiety } \\
\hline No caregiving & 8558 & 152 & 1 (ref.) & 1 (ref.) \\
\hline Caregiving without limitations & 312 & 4 & $0.72(0.27-1.95)$ & $0.91(0.33-2.46)$ \\
\hline Caregiving with limitations & 470 & 14 & $1.68(0.97-2.90)$ & $1.86(1.06-3.25)$ \\
\hline
\end{tabular}

${ }^{a}$ Six participants were excluded because the diagnosis of the outcome occurred before assessment of the exposure

${ }^{\mathrm{b}}$ Model 1 was a crude model; model 2 was adjusted for age, sex, social support and socio-economic position 
While we did not assess cognitive impairment in the persons given care to, this is still an interesting finding and could be taken into account in future studies. In contrast, one study conducted in the Netherlands suggested no association between informal caregiving of a relative and mental ill health. ${ }^{17}$ This discrepancy could be explained by their study having a smaller study population and the exposure definition of informal caregiving which not only included family but also partners and friends.

The suggested underlying reason for mental ill-health in caregivers is stress in particular [23]. Stress due to caregiving comes with high levels of unpredictability and consequences of high stress often affect work, family and relationships [23]. Negative changes in the caregivers lifestyle behaviours include bad dietary habits and little physical exercise which might lead to physical strain [23]. Hence, the possible incompatibility of providing informal care and maintaining a balanced social life as well as upholding working duties increases the risk of mental ill-health, according to the World Health Organisation [3, 18]. Consequently, persons suffering from mental ill-health have been shown to be more susceptible to physical illness [23, 29, 30]. However, a study by Maguire et al. suggested that positive appraisal might reduce the perceived stress and limitations in the caregiver's life, as it shows the appreciation for their caregiving [7].

The strength of this study is the combination of population-based register data and self-administered questionnaire data that were collected longitudinally. By using the different data sources, we were able to include several confounding factors and compare self-reported outcomes with clinically diagnosed outcomes. Even though primary care is not covered by the Swedish medical registers, we were able to detect diagnoses made in primary care, through self-reports of specific questions in the questionnaire. Furthermore, the loss to follow-up was minimised for the longitudinal associations due to the utilisation of register information. No differences between the main analysis and the sensitivity analysis could be detected, which means that loss to follow-up could not have affected our results to any large extent.

This study also faces some limitations. As an analysis on non-respondents showed that participation was associated with having no previous psychiatric inpatient diagnosis [26], non-respondents are more likely to face severe anxiety and depression compared to those that participated. Hence, the external validity of this study is limited, as caregivers with perceived limitations or with mental health problems might not participate. However, this limitation is minimised by utilising the Swedish medical registers in order to check for clinically diagnosed outcomes in those that did not return the follow- up questionnaire. In addition, the informal caregiving was only assessed at baseline and hence, we were unable to adjust for possible changes of caregiving during follow-up periods.

Future research should focus on gender differences in the association between caregiving and perceived as well as diagnosed mental ill-health, as this study did not have enough statistical power to detect differences between genders. Additionally, possible reasons that give rise to the perceived limitations should be further explored.

\section{Conclusion}

This study showed that caregivers experiencing limitations seem to have a higher risk of both short-term and long-term depression and anxiety. The findings imply the importance of exploring the degree to which informal caregiving can be provided without causing any mental problems to caregivers. There is a need for developing additional support strategies to avoid additional health burdens not only on an individual level but also in society at large.

\section{Supplementary Information}

The online version contains supplementary material available at https://doi. org/10.1186/s12889-021-11246-1.

Additional file 1: Table S1. The association of informal caregiving with clinically diagnosed depression and anxiety in those who answered the 10-year follow-up questionnaire in wave $3\left(n=5106^{*}\right)$.

\section{Acknowledgements \\ Not applicable. \\ Authors' contributions \\ $Y F, J M$, and $Y L$ designed the study. MS analyzed data and drafted the manuscript. YF, JM, and YL interpreted the results and contributed to the revision of the manuscript. All authors read and approved the final manuscript.}

Funding

Open Access funding provided by Karolinska Institutet.

Availability of data and materials

The datasets used and/or analysed during the current study are available from the corresponding author on reasonable request.

\section{Declarations}

Ethics approval and consent to participate

The ethical review board of Karolinska Institutet approved the project (case numbers: 2010/1185-31/596:260, 01-218,04-528/3 and 09-880). Written informed consent was obtained from all study participants prior to study inclusion. All methods were performed in accordance with the relevant guidelines and regulations.

Consent for publication

Not applicable.

Competing interests

The authors declare that they have no competing interests. 
Received: 4 April 2021 Accepted: 8 June 2021

Published online: 29 June 2021

\section{References}

1. Facts about carers and caring in Sweden - Nationellt kompetenscentrum anhöriga n.d. https://www.anhoriga.se/information-in-english/facts-aboutinformal-carers/facts-carers-and-support-of-carers. Accessed 3 Jul 2020.

2. Li J, Song Y. Formal and Informal Care. In: Gu D, Dupre M, editors. Encyclopedia of Gerontology and Population Aging. Cham: Springer; 2019. https://doi.org/10.1007/978-3-319-69892-2_847-1.

3. OECD. The impact of caring on family carers. Help wanted? Providing and paying for long-term care; 2011. p. 85-120.

4. Verbakel E. How to understand informal caregiving patterns in Europe? The role of formal long-term care provisions and family care norms. Scand J Public Health. 2018:46(4):436-47. https://doi.org/10.1177/1403494817726197.

5. Genet N, Boerma W, Kroneman M, Hutchinson A, Saltman RB. Home care across Europe: current structure and future challenges. Copenhagen: The European Observatory on Health Systems and Policies, WHO Regional Office for Europe; 2012.

6. Petrini M, Cirulli F, D'amore A, Masella R, Venerosi A, Carè A. Health issues and informal caregiving in Europe and Italy. Ann Ist Super Sanità. 2019;55(1): 41-50. https://doi.org/10.4415/ANN_19_01_08.

7. Maguire R, Hanly P, Maguire P. Beyond care burden: associations between positive psychological appraisals and well-being among informal caregivers in Europe. Qual Life Res. 2019;28(8):2135-46. https://doi.org/10.1007/s11136019-02122-y.

8. Zigante V. Informal Care in Europe. Exploring Formalisation, Availability and Quality. Luxembourg: European Commission; 2018.

9. Plöthner M, Schmidt K, de Jong L, Zeidler J, Damm K. Needs and preferences of informal caregivers regarding outpatient care for the elderly: a systematic literature review. BMC Geriatr. 2019;19(1):82. https://doi.org/1 0.1186/s12877-019-1068-4.

10. World Health Organization. The Solid Facts. Home care in Europe. 2008.

11. Eriksson M, Wennerberg M, Lundgren S, Danielson E. "Self-employed" in Caregivinghood: the contribution of Swedish informal caregivers' environmental and contextual resistance resources and deficits. Societies. 2017:7(3):19. https://doi.org/10.3390/soc7030019.

12. Kim G, Allen RS, Wang SY, Park S, Perkins EA, Parmelee P. The relation between multiple informal caregiving roles and subjective physical and mental health status among older adults: do racial/ethnic differences exist? The Gerontologist. 2019;59(3):499-508. https://doi.org/10.1093/geront/gnx1 96.

13. Buyck JF, Ankri J, Dugravot A, Bonnaud S, Nabi H, Kivimaki M, et al. Informal caregiving and the risk for coronary heart disease: the Whitehall II study. J Gerontol A Biol Sci Med Sci. 2013;68(10):1316-23. https://doi.org/10.1093/ gerona/glt025.

14. Capistrant BD, Robin Moon J, Berkman LF, Maria GM. Current and long-term spousal caregiving and onset of cardiovascular disease. J Epidemiol Commun Health. 2012;66(10):951-6. https://doi.org/10.1136/jech-2011-20004 0.

15. Lee S, Colditz GA, Berkman LF, Kawachi I. Caregiving and risk of coronary heart disease in U.S. women: a prospective study. Am J Prev Med. 2003; 24(2):113-9. https://doi.org/10.1016/S0749-3797(02)00582-2.

16. Mortensen J, Dich N, Lange T, Ramlau-Hansen $\mathrm{CH}$, Head J, Kivimäki M, et al. Weekly hours of informal caregiving and paid work, and the risk of cardiovascular disease. Eur J Pub Health. 2018;28(4):743-7. https://doi.org/1 0.1093/eurpub/ckx227.

17. Tuithof M, ten Have M, van Dorsselaer S, de Graaf R. Emotional disorders among informal caregivers in the general population: target groups for prevention. BMC Psychiatry. 2015;15(1):23. https://doi.org/10.1186/s12888-01 5-0406-0.

18. Shahly V, Chatterji S, Gruber MJ, al-Hamzawi A, Alonso J, Andrade LH, et al. Cross-national differences in the prevalence and correlates of burden among older family caregivers in the World Health Organization world mental health (WMH) surveys. Psychol Med. 2013;43(4):865-79. https://doi. org/10.1017/S0033291712001468

19. Lacey RE, McMunn A, Webb E. Informal caregiving patterns and trajectories of psychological distress in the UK household longitudinal study. Psychol Med. 2019;49(10):1652-60. https://doi.org/10.1017/S0033291718002222.

20. Bom J, Bakx P, Schut F, van Doorslaer E. The impact of informal caregiving for older adults on the health of various types of caregivers: a systematic review. Gerontologist. 2019;59(5):e629-42. https://doi.org/10.1093/geront/ gny137.

21. Sharma N, Chakrabarti S, Grover S. Gender differences in caregiving among family - caregivers of people with mental illnesses. World J Psychiatr. 2016; 6(1):7-17. https://doi.org/10.5498/wjp.v6.i1.7.

22. Abajo M, Rodríguez-Sanz M, Malmusi D, Salvador M, Borrell C. Gender and socio-economic inequalities in health and living conditions among coresident informal caregivers: a nationwide survey in Spain. J Adv Nurs. 2017; 73(3):700-15. https://doi.org/10.1111/jan.13172.

23. Verbakel E, Tamlagsronning S, Winstone L, Fjaer EL, Eikemo TA. Informal care in Europe: findings from the European social survey (2014) special module on the social determinants of health. Eur J Pub Health. 2017; 27(suppl_1):90-5. https://doi.org/10.1093/eurpub/ckw229.

24. Zwar $L$, König HH, Hajek A. Psychosocial consequences of transitioning into informal caregiving in male and female caregivers: findings from a population-based panel study. Soc Sci Med. 2020;264:113281. https://doi. org/10.1016/j.socscimed.2020.113281.

25. McLean CP, Asnaani A, Litz BT, Hofmann SG. Gender differences in anxiety disorders: prevalence, course of illness, comorbidity and burden of illness. J Psychiatr Res. 2011;45(8):1027-35. https://doi.org/10.1016/j.jpsychires.2011. 03.006.

26. Lundberg I, Damström Thakker K, Hällström T, Forsell Y. Determinants of non-participation, and the effects of non-participation on potential causeeffect relationships, in the PART study on mental disorders. Soc Psychiatry Psychiatr Epidemiol. 2005;40(6):475-83. https://doi.org/10.1007/s00127-0050911-4.

27. American Psychiatric Association. Diagnostic and statistical manual of mental disorders: DSM-5. 5th ed. Arlington: American Psychiatric Association; 2013. https://doi.org/10.1176/appi.books.9780890425596.

28. Utg., Statistiska centralbyrån. Yrkesklassificeringar i FoB 85 Enligt Nordisk Yrkesklassificering (NYK) Och Socioekonomisk Indelning (SEI) : Alfabetisk Version = Occupations in Population and Housing Census 1985 (FoB 85) According to Nordic Standard Occupational Classification...and Swedish Socio-Economic Classification... : Alphabetical Version. Stockholm: Statistiska centralvyrån; 1989.

29. Deleskog A, Ljung R, Forsell Y, Nevriana A, Almas A, Möller J. Severity of depression, anxious distress and the risk of type 2 diabetes - a populationbased cohort study in Sweden. BMC Public Health. 2019;19.

30. Almas A, Forsell $Y$, lqbal $R$, Janszky I, Moller J. Severity of depression, anxious distress and the risk of cardiovascular disease in a Swedish populationbased cohort. PLoS One. 2015;10(10):e0140742. https://doi.org/10.1371/ journal.pone.0140742.

\section{Publisher's Note}

Springer Nature remains neutral with regard to jurisdictional claims in published maps and institutional affiliations.
Ready to submit your research? Choose BMC and benefit from:

- fast, convenient online submission

- thorough peer review by experienced researchers in your field

- rapid publication on acceptance

- support for research data, including large and complex data types

- gold Open Access which fosters wider collaboration and increased citations

- maximum visibility for your research: over $100 \mathrm{M}$ website views per year

At $\mathrm{BMC}$, research is always in progress.

Learn more biomedcentral.com/submissions 